\title{
The problem-based learning through the e-portfolio as a methodological basis for the acquisition of the transversal competence of solidarity and social commitment in mathematics subjects
}

\author{
M.I, García-Planas ${ }^{1}$, J. Taberna ${ }^{2}$ and S, Domínguez-García ${ }^{3}$ \\ ${ }^{1}$ Universitat Politècnica de Catalunya, Spain; maria.isabel.garcia@upc.edu \\ ${ }^{2}$ Universitat Politècnica de Catalunya, Spain; judit.taberna@gmail.com, \\ ${ }^{3}$ Escola Els Llorers, Spain; soyelsanti31@gmail.com
}

Problem-based learning (PBL) is a learning methodology based on constructivist theories and focused on learning processes that is gaining strength at all levels of education and on which there are already experiences in several European and American universities. -The PBL methodology together with the tool and portfolio have been the basis to implement the competence "sustainability and social commitment" in the subject of linear algebra in the ETSEIB UPC, in order that students understand and become aware of global issues, not only in its social, economic and environmental aspects, but also from the point of view of mathematics. Results of the experience are presented regarding students' self-perception of the competences studied and the academic results.

Keywords: Problem-based learning, e-portfolio, linear algebra, sustainability and social commitment competences.

\section{Introduction}

The notion of sustainable development became the basis of the United Nations Conference on Environment and Development held in Rio de Janeiro in 1992. This summit marked the first international attempt to develop action plans and strategies to move towards a more sustainable development model. Specifically, at the Earth Summit in Rio de Janeiro in 1992 an appeal was made to education professionals of all levels and disciplines to help citizens acquire an adequate vision of the challenges and problems that afflict humanity and can thus participate in the necessary informed decision making (Vilches and Gil, 2003).

Concretely, the sustainable development concept is defined as development that meets the needs of the current generation without compromising the ability of future generations. However, the lack of understanding and even misinterpretation of this definition has delayed the implementation of sustainable practices within the framework of Higher Education.

It is usual to associate the term "education" with what happens in the classroom. Nevertheless, "learning" in Education for sustainable development takes into account a wide variety of social contexts. It includes what happens in the formal education system but also extends to daily and professional life, (Tilbury, 2011). 
Universities must act as agents of change by promoting the principles of sustainable development within their institutions and in society through education and the development of competencies that will contribute to a more sustainable future, (Barth and Reickman, 2012).

Problem-based learning (PBL) is a learning methodology based on constructivist theories and focused on learning processes that is gaining strength at all levels of education and on which there are already experiences in several European and American universities.

The PBL methodology seeks the development of active learning through the resolution of complex situations close to reality, on which they must also assess the solution according to the context (see Domínguez et Al. 2014, for more details).

-The digital portfolio is becoming a basic, plural and global tool in the acquisition of transversal competences, establishing a methodology of continuous evaluation through digital rubrics incorporated into the portfolio. The e-portfolio tool, which includes evaluation rubrics, allows students to collect, select, reflectively interpret, and present the results obtained in the resolution of the proposed problem by self-evaluating during its elaboration through the rubrics. Remember that a rubric is an evaluation tool that lists the criteria and standards for evaluating work related to learning objectives. Depending on what you want to evaluate, the rubrics can be holistic in which you do not separate the parts of a job evaluating the whole of the work, or analytics that evaluate each part of an activity or a set of activities. The rubrics are applicable to all levels and educational fields, from stages of initiation to reading to the evaluation, for example, of doctoral theses or innovation projects. In particular, in university degrees the rubrics allow to evaluate both specific and generic competences, so they become a good tool for the evaluation of competence in sustainability and social commitment, see-_Brookhart (1999); Domínguez-García, (2014) and Koh (2013), for example.

In the search for alternatives to improve the teaching and learning of linear algebra, different experiments have been designed and implemented, concluding that to improve the teaching and learning of linear algebra can be useful to include alternatives such as creation of e-portfolios, implementing projects both individually and in groups, and the use of new technologies (Domínguez et al. 2016).

The PBL methodology together with the tool and portfolio have been the basis to implement the competence "sustainability and social commitment" in the subject of linear algebra in the ETSEIB UPC, in order that students understand and become aware of global issues, not only in its social, economic and environmental aspects, but also from the point of view of mathematics.

It is well known that linear algebra is fundamental in different areas of science due to the multiple problems that can be modeled by linear systems where linear algebra becomes essential to obtain and discuss the solution. However, one of the main difficulties for first-year university students who have enrolled in scientific or technical degrees other than mathematics is that they do not see the importance of mathematics, in general, and linear algebra, in particular, may have in their fields of interest. The implementation of the competence "sustainability and social commitment" in the subject of linear algebra gives a motivation to students and working problems students understand 
the concepts of linear algebra and see its applicability so they themselves create the need to learn such matter.

\section{Acquisition of sustainability competence through the mathematics subject}

The competence about sustainable development and social commitment is understood as the ability to know and understand the complexity of social and economic phenomena that are typical of the welfare state.

With the projects, it is possible to work the different levels of achievement. - The first level of achievement corresponds a systematic analysis and critical global situation, considering the sustainability of interdisciplinary and sustainable human development, and recognizing the social and environmental implications of the professional activity of the same field. The other two levels of achievement consist of applying sustainability criteria and professional codes of conduct in the design and assessment of technological solutions for level two, and taking social, economic and environmental factors into account in the application of solutions, undertaking projects that tie in with human development and sustainability for level three.

Many people are convinced that Sustainable Development is completely disconnected with mathematical reasoning. However, they are very connected, and they need each other, and it is essential not only to show this relationship to the students but must work both competencies simultaneously.

In this sense, we are committed to the use of the PBL methodology since this allows some guarantee that

a) An integrative concept of the various areas of knowledge is created.

b) An awareness of respect for other cultures, languages and people is promoted.

c) Empathy develops towards others.

d) Work relationships are developed with people of various kinds.

e) Disciplinary work is promoted.

f) Research capacity is promoted.

g) It provides a tool and a methodology to learn new things effectively

When preparing the project, the questions that the teacher should ask to ensure its success are:

1) Is it provided at the beginning, a frame of reference before the activities, which helps to locate the terms and evaluate the acquisition of competition?

2) Does the work proposed to students induce?

- To reflection both from an environmental, social, economic, technological and temporal point of view

- To the identification of technical needs from an environmental, social and economic point of view 
- To the description of the environmental, social and economic impact as a result of the decisions taken?

3) Does the proposed work allow describing the links of the problem posed with other social realities?

If the answers are not all the positive that one expects, the work proposed should be reviewed until such positivity is achieved.

Once the project has been completed by the students, the teacher should ask himself the following question: have the expectations been met? If the response is not satisfactory enough, the proposal should be reviewed to detect the deficiency and be able to correct it for future projects.

In this work is studying how you can relate first-year college-level math with the acquisition of sustainability competencies.

\section{Case study}

The participants in this study are the first-year students of a Bachelor's degreee in Industrial Technology Engineering at ETSEIB during the academic years: 2014-15, 2015-16, 2016-17.

With the aim of addressing the Sustainable Development Goals in the subject of linear algebra, we have prepared a series of contextualized projects that refer to the different Sustainable Development Goals for students to develop throughout of the linear algebra course.

The different project activities carried out by the students are made visible through an e-portfolio that each student creates for that purpose. The teacher follows up on this activity, feeds back and evaluates through previously established e-rubrics. The management of the tasks is done through a learning management system (LMS), the UPC has developed its own virtual environment that has been named "Atenea" using the Moodle open software platform as a technological base.

The greatest difficulty in carrying out this project is the choice of problems and their presentation. The same problem can be introduced from different points of view and here it is a matter of selecting in an appropriate way the point of view of sustainable development. Thus, for example, the study of the control of an elevator with variable load can be considered so that it follows a periodic trajectory. Thus raised is a common exercise, but if it is stated that a school must install an elevator to be accessible for all students with reduced mobility, the problem happens to have a component more to reflect from the point of view of SDGs, since it becomes important to think how long the elevator should be on each floor so that a student with reduced mobility can enter without being closed the door.

All proposed projects are based on real problems related to the specific objective of the SDGs to be addressed. Some of them have been simplified so that they can be solved with the knowledge acquired in a linear algebra course, it is clear that the statements can be readjusted based on the level of knowledge of the specific course that will be put into practice.

The list of prepared projects has been compiled in (Garcia-Planas, Taberna, Rina, 2018), each of these projects is related to one of the 17 Objectives of the SDGs. 
There are no results with Impact on students regard due to the withdrawal of the evaluable competence of "Sustainability and Social Commitment" of the teaching guide of the subject of Linear Algebra by the University. We are struggling to recover transversal competencies as soon as possible.

There are very positive results on sustainability during the course that the University allowed to evaluate the competence, and for the type of proposed projects it is possible to think that if they were implemented, they would also be very positive.

\section{Example of Project proposal}

This project has been designed for a context of engineering school where a course of linear algebra is taught.

The proposal responds to the need to introduce to the linear algebra matter a competence that adds criteria and values consistent with sustainability and answer for the economic, social, cultural and environmental aspects of human development. Concretely, the topic considered is water because it is a critical resource that cannot be substituted. Having potable water is a universal human right and is also a key factor for public health. The way we maintain and expand this critical good is a fundamental problem for building an environmentally and socially sustainable world. Certainly, the organized task for PBL is precisely aligned with one of the Sustainable Development Objectives 2030, more concretely with the goal number six "Ensure access to water and sanitation for all". To achieve this aim is essential training to increase the efficiency of water resources in all sectors and ensure the sustainability of freshwater harvesting and water supply to address water scarcity by reducing the number of people suffering from water shortages.

The formulation project presented to students is as follows:

In a particular country, it is proposed to build a reservoir to regulate the basin of one of its rivers to satisfy the needs of water for irrigation.

For the realization of the project, the students are given the following data:

- $\quad$ Maximum reservoir capacity,

- Quantities required for irrigation

- Volume to be left to maintain water quality standards for other uses, provided that the water level of the dam plus the weekly contribution by the water of the river, does not reach a minimum that does not allow the exit of water;

The primary objective to be achieved with this project is: "Study the viability of the reservoir" by analyzing

1- The stability of the reservoir under the given conditions 
2- The sustainability of the reservoir under the same conditions

3- The stability of the reservoir imposing the variation in the time of the river's contribution to climate change.

4- The sustainability of the reservoir by imposing the previous condition

It is also intended that the following awareness-raising objectives be achieved:

1- $\quad$ Make an assessment of the social benefit by counterbalancing the benefits to be obtained by irrigation in the face of social conflict caused by expropriations and the resulting displacement of the inhabitants of the area.

2- $\quad$ Make an assessment of the problem by extrapolating the case to a large dam.

To solve the project, the student must:

1- Describe using a matrix equation of the type $p(k+1)=A p(k)$, the weekly transition of the probable water units.

2- $\quad$ Express $\mathrm{p}(\mathrm{k})$ as a function of $\mathrm{p}(0)$

3- Starting from a particular amount of water impounded:

i) Analyze the probability that in two weeks the reservoir will be below minimums.

ii) Critical assessment of the result within the context of the work.

4- $\quad$ Find out how Linear Algebra will give us a solution to the matrix equation proposed

5- $\quad$ Apply it to the case at hand

6- Use the calculations to analyze the situation of the reservoir at the week $\mathrm{k}=10$.

7- $\quad$ Study and analysis of stability and sustainability.

With this project not only introduces and evaluates the competence on sustainability but also the social commitment because they must also value the social cost that involves the displacement of people with the uprooting that this entails.

\section{Conclusions}

Sustainability is often emphasized as an essential objective of higher education, but more as a principle that at a practical level. With this work, it is shown how it is possible to carry out the implementation of sustainability competence in an evaluable form, in a subject of higher education mathematics.

Using the e-portfolio the improvement of the autonomy of the students is obtained. They have the opportunity of working on individual tasks but also in group projects, so they can also to cooperate and to work together solving the different tasks. 
Is important to create the need to study mathematics to the students, in this sense, the decision to do projects related to real life has been taken, this fact motive the students to ask questions and understand that the subject they were studying had a practical application. We should not look for real problems to present as exercises in the application of mathematics, but we should ask: What mathematics can help solve a real problem?

The use of technological tools, the e-portfolio, implies that the professor has to prepare all the material very carefully including templates, and also a subject planning with all the structure of the course.

With the implementation of this methodology, an improvement of the qualifications of the students has been observed. What is more, students have achieved the concrete and general skills of Linear Algebra and about the competence of sustainability and social commitment.

\section{References}

Barth, M. and Rieckmann, M. (2012). Academic staff development as a catalyst for curriculum change towards education for sustainable development: an output perspective. Journal of Cleaner Production 26, 28-36.

Brookhart, S.M. (1999). The Art and Science of Classroom Assessment: The Missing Part of Pedagogy. ASHE-ERIC Higher Education Report Washington, DC: The George Washington University, Graduate School of Education and Human Development, 27(1).

Domínguez-García, S. (2014). Creació d'una rúbrica per avaluar la competència docent en l'ús de la Pissarra Digital Interactiva, TFG. Universitat Rovira i Virgili. 2014.

Domínguez García, S., García Planas, M. I., Palau, R., and Taberna Torres, J. (2014). Uso del eportafolio en la formación: el e-portafolio integral. In Revista del Congrés Internacional de Docència Universitària i Innovació (CIDUI), núm. 2 (2014). Congrés Internacional de Docència Universitària i Innovació (CIDUI).

Domínguez-García, S., García-Planas, M.I. and Taberna, J. (2016). Mathematical modelling in engineering: an alternative way to teach Linear Algebra. International Journal of Mathematical Education in Science and Technology, 47(7), 1076-1086. DOI: 10.1080/0020739X.2016.1153736

Garcia-Planas, M.I., Taberna, J., and Domínguez-García, S. (2016). The use of e-portfolio in a linear algebra course". Journal of Technology and Science Education, 6(1), 52-61.

García Planas, M. I. and Taberna Torres, J. (2017). La gestión sostenible del agua a través del aprendizaje basado en proyectos en la asignatura de álgebra lineal. En I International Congress on Water and Sustainability. UPC. Departament d'Enginyeria de Projectes i de la Construcció.

Garcia-Planas, M.I., Taberna, J. and Rina, N. (2018). Álgebra lineal en la educación para el desarrollo sostenible. Iniciativa Digital Politècnica, Barcelona, España.

Koh, J.H.L. (2013). A rubric for assessing teachers' lesson activities with respect to TPACK for meaningful learning with ICT. Australasian Journal of Educational Technology, 29(6), 887-900. 
Tilbury, D. (2011). Education for sustainable development: An expert review of processes and learning. UNESDOC Digital Library.

Vilches, A. y Gil, D. (2003). Construyamos un futuro sostenible. Diálogos de supervivencia. Cambridge University Presss, Madrid, España. 